\title{
EDITORIAL
}

Editor-in-Chief

\section{Words matter. Spinal Cord asks authors to choose their words carefully}

\author{
Lisa A. Harvey ${ }^{1}$ \\ (c) International Spinal Cord Society 2019
}

The words we use matter. They reflect an attitude and convey a message. Spinal Cord asks authors to ensure that the words they use are respectful to all and in particular to those with spinal cord injuries. This Editorial will highlight some of the common words and phrases we ask authors to use when referring to people with spinal cord injuries and others.

We ask authors to use person-centered terminology (sometimes called people-first language) when referring to people with a spinal cord injuries or another type of disability or condition. For example, we prefer "people with tetraplegia" (not "tetraplegics"), "people with paraplegia" (not "paraplegics"), and "people with spinal cord injuries" (not "spinal cord injured"). We discourage people from writing or saying:

"I work with cords"- when trying to convey that they work with people with spinal cord injuries.

Person-centered terminology conveys the message that people with spinal cord injuries are people first, and not defined by their injuries.

In a similar way, we ask authors to use the term "participants" (not "subjects"). The word "participant" implies that a person willingly took part in a study and was not merely considered an experimental object.

We ask authors to refer to their team members in a way that conveys a real partnership of mutual respect. When healthcare professionals describe those that they work with professionally, we ask them to avoid phrases such as
— "my nurses", "my therapists", or "my doctors". These all imply ownership and an imbalanced relationship. Instead, we ask authors to write and say "the nurses, therapists and doctors that work with me", or something similar that reflects the key attributes of effective multidisciplinary team work.

We accept the word "patient" if a person is in hospital at the time the study was conducted. However, as soon as a person enters a study, it is appropriate to refer to her or him as a participant, unless the terminology becomes particularly cumbersome. We will accept the term "consumer" although we do not encourage the use of this word because it implies the relationship between the person with spinal cord injury and healthcare professionals or service provider is primarily a commercial one.

We also encourage authors to use adjectives to describe people in a sensitive way. So instead of phrases such as "healthy people" when referring to those without a spinal cord injury, we prefer "able-bodied people". This terminology avoids implying that a person with a spinal cord injury is not, or cannot be, healthy.

We acknowledge that some authors are writing in their second language and that the nuances of the English language are not always clear (if it is any consolation, these nuances are not always clear to those of us for whom English is our first language). Nonetheless, we encourage all to be aware of the power of words and the messages they convey. Spinal Cord will continue to ask authors to choose their words carefully to ensure that they reflect the sorts of attitudes and beliefs we all value.
Lisa A. Harvey

spinalcord@iscos.org.uk

1 University of Sydney, Sydney, Australia 